\title{
Tracking and Commentary on China's Overseas Consumption Education Service Trade Research
}

\author{
Hong Ji* \\ Science and Technology College \\ Jiangxi Normal University \\ Nanchang, China \\ jxsdjh@vip.sina.com
}

\author{
Mengxin Cao \\ Education College \\ Jiangxi Normal University \\ Nanchang, China
}

\begin{abstract}
The history of overseas consumer education service trade has been a hot topic in the field of education in recent years. This paper takes overseas consumption education service trade as the research object, analyzes the development of education service trade through literature analysis, and summarizes the main contents and characteristics of research in this field. The purpose is to grasp the timeline of the development of education service trade and discover the problems and deficiencies in the research.
\end{abstract}

Keywords-Education service trade; Overseas consumption; Literature review

\section{INTRODUCTION}

At present, all countries attach great importance to the development of overseas consumer service trade in higher education. With the acceleration of the globalization process, the frequency of import and export of educational services has also increased significantly in international transactions, and gradually has its development characteristics. The trade in education services accounts for an increasing proportion of international trade in services. It is rich in the way of trade and content. The countries of the world have reached a consensus on the importance of education services and promoted the development process to varying degrees.China's Ministry of Education's party secretary and minister Baosheng Chen also pointed out in "China Education 2049" that "in 2049, China will become the most desirable destination for people from all over the world. Countries will have the will to communicate and integrate with Chinese culture. There will be a large number of teachers and students coming to China to learn and exchange China's development experience and achieve common progress in the process of communication. It can be seen that the development of this field can not only bring greater economic income, but also promote the export and dissemination of Chinese culture, which is conducive to China's social modernization and the development of Chinese culture.

\section{TRACKING ANALYSIS OF RESEARCH LITERATURE ON OVERSEAS CONSUMER EDUCATION SERVICE TRADE IN CHINA}

A total of 723 articles were searched based on the "CNKI.net.", which is currently the world's largest Chinese database, covering a wide range of resources database. Among the 723 documents, there are 489 journal articles, 210 master's thesis papers, 18 conference papers, 1 newspaper news, and 5 books. Through the analysis of the publication time of the paper, we can understand that the first article of the research on the development of education service trade appeared in 1998, namely Yongcai Gu's "A Brief Discussion on International Education Service Trade."[1] The first doctoral thesis was in 2002, published by Yaling Chen of Xiangtan University, "Internationalization of Higher Education: History and Current Situation of China."[2] From the stage point of view, before the 21 st century is considered the exploration stage of research. China's accession to the WTO in 2001 began the active stage in the research and development of education service trade. The development research in this field immediately became a hot spot of concern. Through more than ten years of development, the characteristics of the research literature in the development of overseas consumer education service trade are mainly concentrated in the following points:

\section{A. Research on the Current Situation and Problems of Overseas Consumer Education Service Trade}

Most of the analysis of the current situation of studying in China is based on the number of Chinese students studying in China in recent years, the distribution of sources, the distribution of professionalism, the distribution of academic qualifications, to name a few. There are also articles that use comparative data to compare with the number and distribution of international students in developed countries. For example, Xiaojia Chen (2016) conducted a comparative study on the structural indicators of these international students in his master's thesis.[3]

\section{B. Comparative Study on Foreign Trade Education Service Trade Policy}

The research on the study abroad policies of various countries is quite extensive, and the research on the United States, Britain, Australia and other countries is the most prominent. In a comparative study with the United Kingdom, Jiqiang Liu(2008) analyzed the British education internationalization strategy and pointed out that under the premise of internationalization of the curriculum and guaranteeing the quality of teaching, It has taken effective measures to attract foreign students. The measures included: colleges and universities to strengthen overseas education and publicity; three scholarships (government scholarships, academic group scholarships, college scholarships) which are attractive to international students; engaging colleges and 
universities actively participate in cooperation projects of foreign universities.[4] In a comparative study with Australia, Yiou Zhao (2015) analyzed the scale, direction and structure of the development of Australian and Chinese education services trade. It is believed that Australia's development advantage lies in national policy support, high quality of college education, industrialization of educational services, and promotion of national language.[5]

\section{Research on the Promotion Measures of Overseas Consumption Education Service Trade}

Guojun Zhang (2014) believes that the countermeasures for developing China's overseas consumer education service trade are: optimizing the management system and rationally allocating resources; Use market operations to open up international markets; Give play to comparative advantages, strengthen the development of specialty professions, and broaden the discipline setting; Build a research university and accelerating the process of mutual recognition of academic qualifications; Improve the medical insurance system for foreign students.[6]

\section{A REVIEW OF CHINA'S OVERSEAS CONSUMPTION EDUCATION SERVICE TRADE RESEARCH}

Through the analysis of the literature on the research of overseas consumer education service trade in China, we can conclude that:

\section{A. Existing Problems in China's Overseas Consumer Education Service Trade}

Lack of high-level teacher strength.From the perspective of teacher structure, there are inequities in the academic structure, age structure and disciplinary structure of college teachers in China. The teacher resources are inclined to the key universities in China, and the resource allocation of teachers is unbalanced. There are fewer high-level teachers from abroad, which is not conducive to academic international exchanges, nor to the construction of disciplines and the construction of teaching features in universities, and it is difficult to attract international students. Secondly, from the perspective of teachers, teachers who are proficient in bilingual teaching in China are very limited, and the level of teachers is lower than that in developed countries. Therefore, China's overseas consumer education services lack competitiveness in the international market.

Lack of education quality supervision system.The competition in the international education market is ultimately the competition for the quality of education. Both the government and the university must recognize that the guarantee of quality of education is of great significance to the international market. Most developed countries have set up quality supervision systems for higher education.

However, China still lacks a relatively complete education quality certification system and lacks a comprehensive evaluation report on higher education. Foreign students lack channels and information to understand Chinese higher education, which weakens the willingness of international students to study in China.
Lack of government policy support.At present, China's overseas consumer education service trade management system lacks policy and data support. First, China has not yet issued a general law on trade in education services. The incompatibility of such policies has led to opaque policies on the development of education services trade in China, which has hindered the healthy development of the import and export of education services trade. Second, the Chinese government has too many restrictions in the management of higher education institutions. The lack of autonomy and subsequent lack of positive initiative of colleges and universities has led to the slow state of development of China's higher education.

\section{B. Countermeasures for the Development of China's} Overseas Consumption Education Service Trade

Scholars have studied and analyzed the countermeasures for the development of China's overseas consumer education service trade from different angle sand put forward various solutions. There are many research results, but most of them start with suggestions from the following three aspects:

Building a personalized faculty.The faculty is the most important productive resource in colleges and universities, and it is the main force for the university to realize the talent training strategy. In the face of increasingly fierce international competition, Chinese universities must implement a talent strategy and actively train quality teachers.[7] First of all, it is necessary to improve the entry threshold for college teachers, and strictly require the qualification certification and level certification of the applied teachers. Secondly, it is necessary to formulate a strategic plan for the development of the teaching staff, train the teachers in batches and in a timely manner, and promote their business capabilities in a sustained and stable manner. Thirdly, teacher resources must be allocated rationally, improve the overall quality of the teacher group, and promote the rationalization of the faculty structure.

Create a high level of education quality.Colleges and universities should reform the unreasonable curriculum system, create an international student curriculum system that is in line with the international curriculum, improve teaching methods, update teaching content, and prepare excellent textbooks for international students. The state shall establish an independent and professional third-party higher education quality supervision institution and social intermediary institution, which is responsible for supervising the quality of teaching in colleges and universities, This group can provide their own suggestions and countermeasures for the international development of colleges and universities, and publish educational quality test reports to the public to provide reference materials for students at home and abroad to choose the school that suits them. At the same time, it can guide and balance higher education schools, and conduct macro analysis and management of higher education.[8]

Play more positive government effectiveness. The government must properly handle the relationship between laws and regulations, government regulations, and higher education services, and emphasize the government's 
regulation of the services and guarantees for higher education services and their commitments. In China, the government is still one of the main components of the macro management of higher education, and it is the most important part. However, the way in which it works, the size of its power, the size of its responsibility, and the relationship with management activities have all changed a lot. The government's intervention in the market's resource allocation function of higher education services is necessary, but there is an inherent contradiction in this intervention. To this end, the boundaries and critical points of government intervention must be clarified.Some scholars have proposed three-qualifications on view of the scope of government action. One, the role of government should be strictly limited to the extent of market failure; Two, government intervention should be limited to market defects that can be repaired; Three, government intervention should also follow the principle of costeffectiveness. As far as higher education services are concerned, within the scope of commitments, government regulation mainly points to three aspects: provide things that the market cannot provide; provide things that the market is unwilling to provide; provide things that should not be provided by the market,such as higher education policies and development strategies.[9]

\section{CONCLUSION}

\section{A. More Theoretical Research, Less Empirical Research}

From the analysis of literature, the research on overseas consumer education service trade is still based on theoretical discussion. Many research results focus on theoretically analyzing the reasons and countermeasures for the development of this field in China.In contrast, empirical research is lacking, and the recommendations on specific measures are also greatly reduced. Without the verification of practice, it is necessary to strengthen the empirical investigation and research. Combine quantitative research with qualitative research to better solve the problems in the development of overseas consumer education service trade from the practical level.

\section{B. More Research at the National Level, Less Research at the School Level}

The research on the development of overseas consumer education service trade in China is mainly concentrated at the national level. Whether it is to study the gap between the international, various countries and regions, or to explore the institutional and policy reforms of education service trade, it is basically aimed at the national level. Although there are certain discussions on how universities should develop, they are very thin. This lack of discussion presents an opportunity for additional study to advance the field and China's development.

\section{REFERENCES}

[1] Y.C. Gu, “A Brief Discussion on International Education Service Trade J. International Business," Journal of University of International Business and Economics, vol. 03, pp. 30-33, 1998.

[2] Y.L. Chen, Internationalization of Higher Education: History and Current Situation of China, Xiangtan University, 2002.

[3] X.J. Chen, Comparison Research on International Competitiveness of Higher Educational Service Trade Between China and US, Guangdong University of Foreign Studies, 2016

[4] J.Q. Liu, "Enlightenment from the Internationalization of British Higher Education," J. Modern economic information, vol. (3), 2008.

[5] Y.O. Zhao, Comparative Analysis of the Competitiveness of ChinaAustralia Education Service Trade, Beijing Jiaotong University, 2015.

[6] G.J. Zhang, "Study on Chinese Consumption abroad of Education Service Trade," J.China Higher Education Research, vol. 1, 2014.

[7] S.L. Bai and Y.F. Lu, Study Abroad Education in China, Beijing Language and Culture University Press, Beijing, 2013.

[8] J. Niu, "Comparison Study on Trade Competitiveness of Educational Services in Abroad Consumption Trade Between China and India towards America," J.Higher Education of Science, vol. (4), pp. 63-69, 2016.

[9] Y. Zhang, Research on Theory and Policy of Higher Education Service Trade, China Economic Publishing House, Beijing, 2009. 